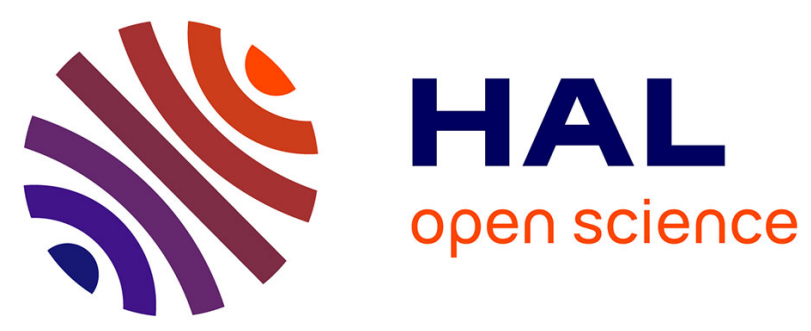

\title{
Effectiveness of involving a nurse specialist for patients with urinary incontinence in primary care: results of a pragmatic multicentre randomised controlled trial
}

Pytha Albers-Heitner, Toine Lagro-Janssen, Manuela Joore, Bary Berghmans, Fred Nieman, Pieter Venema, Johan Severens, Ron Winkens

\section{To cite this version:}

Pytha Albers-Heitner, Toine Lagro-Janssen, Manuela Joore, Bary Berghmans, Fred Nieman, et al.. Effectiveness of involving a nurse specialist for patients with urinary incontinence in primary care: results of a pragmatic multicentre randomised controlled trial. International Journal of Clinical Practice, 2011, 65 (6), pp.705. 10.1111/j.1742-1241.2011.02652.x . hal-00640466

\section{HAL Id: hal-00640466 https://hal.science/hal-00640466}

Submitted on 12 Nov 2011

HAL is a multi-disciplinary open access archive for the deposit and dissemination of scientific research documents, whether they are published or not. The documents may come from teaching and research institutions in France or abroad, or from public or private research centers.
L'archive ouverte pluridisciplinaire HAL, est destinée au dépôt et à la diffusion de documents scientifiques de niveau recherche, publiés ou non, émanant des établissements d'enseignement et de recherche français ou étrangers, des laboratoires publics ou privés. 


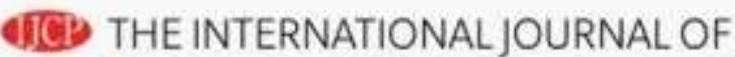 CLINICAL PRACTICE}

\section{Effectiveness of involving a nurse specialist for patients with urinary incontinence in primary care: results of a pragmatic multicentre randomised controlled trial}

\begin{tabular}{|c|c|}
\hline Journal: & International Journal of Clinical Practice \\
\hline Manuscript ID: & IJCP-11-10-0626.R1 \\
\hline Wiley - Manuscript type: & Original Paper \\
\hline $\begin{array}{r}\text { Date Submitted by the } \\
\text { Author: }\end{array}$ & 14-Jan-2011 \\
\hline Complete List of Authors: & $\begin{array}{l}\text { Albers-Heitner, Pytha; Maastricht University Medical Centre, } \\
\text { Department of Integrated Care } \\
\text { Lagro-Janssen, Toine; Radboud University Nijmegen Medical } \\
\text { Centre, Department of Primary and Community Care } \\
\text { Joore, Manuela; Maastricht University Medical Centre, Department } \\
\text { of Clinical Epidemiology and Medical Technology Assessment; } \\
\text { Maastricht University Medical Centre, Department of Health } \\
\text { Organisation, Policy, and Economics } \\
\text { Berghmans, Bary; Maastricht University Medical Centre, Pelvic care } \\
\text { Centre Maastricht (PcCM) } \\
\text { Nieman, Fred; Maastricht University Medical Centre, Department of } \\
\text { Clinical Epidemiology and Medical Technology Assessment } \\
\text { Venema, Pieter; HAGA Hospital, Poliklinisch Continentie Centrum } \\
\text { Severens, Johan; Erasmus University Rotterdam, Institute of Health } \\
\text { Policy and Management } \\
\text { Winkens, Ron; Maastricht University Medical Centre, Department of } \\
\text { General Practice }\end{array}$ \\
\hline Specialty area: & \\
\hline
\end{tabular}

\section{SCHOLARONE" Manuscripts}


| IJCP RCT 20112010revised14012011

1

2

3

4

5

6

7

8

9

Effectiveness of involving a nurse specialist for patients with urinary incontinence in primary care: results of a pragmatic multicentre randomised controlled trial

(Pytha) C.P. Albers-Heitner, MSc, PPT ${ }^{\circledR 1 \S}$

(Toine) A.L.M. Lagro-Janssen, Prof, $\mathrm{PhD}, \mathrm{MD}^{2}$

(Manuela) M.A. Joore, $\mathrm{PhD}^{3,4}$

(Bary) L.C.M. Berghmans, PhD, PPT ${ }^{\circledR 5}$

(Fred) F. Nieman, $\mathrm{PhD}^{3}$

(Pieter) P.L. Venema, $\mathrm{PhD}$, urologist $^{6}$

(Johan) J.L. Severens, Prof, $\mathrm{PhD}^{4,7}$

(Ron) R.A.G. Winkens, $\mathrm{PhD}, \mathrm{MD}^{1,8}$

1 = Department of Integrated Care, Maastricht University Medical Centre, Maastricht, The Netherlands

$2=$ Department of Primary and Community Care, Radboud University Nijmegen Medical Centre, Nijmegen, The Netherlands 3 = Department of Clinical Epidemiology and Medical Technology Assessment, Maastricht University Medical Centre, Maastricht, The Netherlands 4 = Department of Health Organisation, Policy, and Economics, Maastricht University Medical Centre, Maastricht, The Netherlands 5 = Pelvic care Centre Maastricht (PcCM), Maastricht University Medical Centre, Maastricht, The Netherlands 6 = Poliklinisch Continentie Centrum, HAGA Hospital, The Hague, The Netherlands 
| IJCP RCT 20112010revised14012011

7 = Institute of Health Policy and Management, Erasmus University Rotterdam, Rotterdam, The Netherlands

8 = Department of General Practice, Maastricht University Medical Centre, Maastricht, The

Netherlands

The departments 1, 3, 4 and 8 are involved in Maastricht University Medical Centre/CAPHRI

School for Public Health and Primary Care, Maastricht, The Netherlands

Corresponding Author: ${ }^{\S}$ Corresponding author:

Pytha (C.P.) Albers-Heitner, MSc, PPT ${ }^{\circledR}$, researcher

Maastricht University Medical Centre

Department of Integrated Care (MECC, 1.85.025)

Gaetano Martinolaan 85

P.O. Box 5800

6202 AZ Maastricht

The Netherlands

$\mathrm{T}+31433877547$

$\mathrm{F}+310433874438$

E c.albers@maastrichtuniversity.nl

Disclosures: All authors stated that they had no conflict of interest. 


\begin{abstract}

\section{Background}

Urinary incontinence (UI) primary care management is substandard, offering care rather than cure despite the existence of guidelines that help to improve cure. Involving nurse specialists on incontinence in general practice could be a way to improve care for UI patients.
\end{abstract}

\title{
Aims
}

We studied whether involving nurse specialists on UI in general practice reduced severity and impact of UI.

\section{Methods}

Between 2005 and 2008 a pragmatic multicentre randomised controlled trial was performed comparing a one-year intervention by trained nurse specialists with care-as-usual after initial diagnosis and assessment by general practitioners in adult patients with stress, urgency or mixed UI in four Dutch regions (Maastricht, Nijmegen, Helmond, The Hague). Simple randomisation was computer-generated with allocation concealment. Analysis was done by intention-to-treat principles. Main outcome measure was the International Consultation on Incontinence Questionnaire Short Form (ICIQ-UI SF) severity sum score.

\section{Results}

186 patients followed the intervention and 198 received care-as-usual. Patients in both study groups improved significantly in UI severity and impact on health-related quality of life. After correction for effect modifiers (type of UI, Body Mass Index) we found significant differences between groups in favour of the intervention group at three months $(p=0.04)$; no 
IJCP RCT 20112010revised14012011

differences were found in the one-year linear trend $(\mathrm{p}=0.15)$. Patients in the intervention group without baseline anxiety/depression improved significantly better compared to care-asusual after one year $(\mathrm{p}=0.03)$.

\section{Conclusion}

Involving nurse specialists in care for UI patients supplementary to general practitioners can improve severity and impact of UI, after correction for effect modifiers. This is also the case in specific situations such as anxiety/depression.

\section{Ethical approval and Clinical Trial Registration Number:}

The study protocol was approved by the Medical Ethical Committees of all involved centres. Included patients gave their written informed consent. The trial is registered at http://www.controlled-trials.com/isrctn/62722772 and is reported following CONSORT guidelines for RCTs.

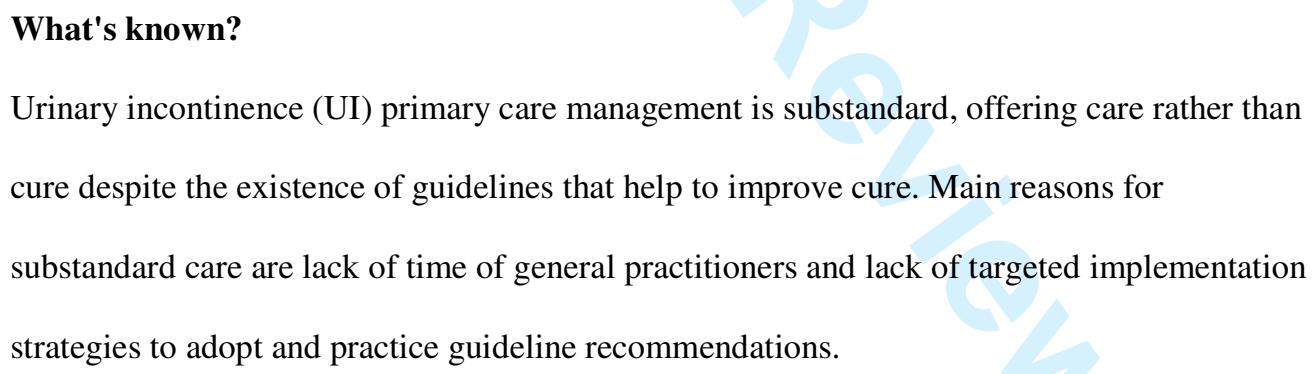
strategies to adopt and practice guideline recommendations.

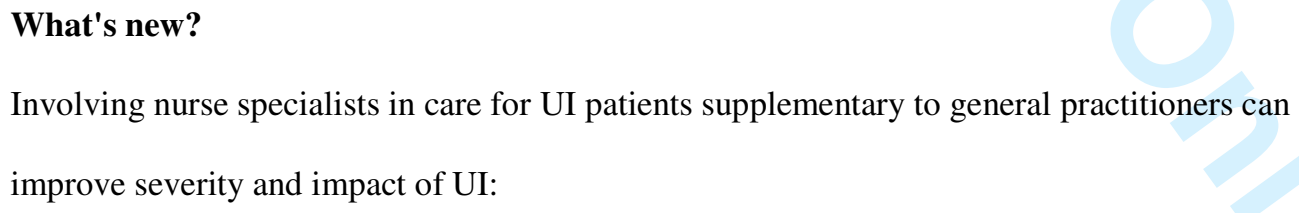




\section{Page 5 of 24}

| IJCP RCT 20112010revised14012011

involving nurse specialists in UI primary care reduced severity and impact of UI after three months of intervention, after correction for effect modifiers; this is also the case in specific situations such as anxiety/depression. 


\section{Introduction}

Urinary incontinence (UI) is a frequent clinical condition. The estimated prevalence of 'any

UI' in middle-aged and older women in the general population appears to be in the range of $30 \%$ to $50 \%$ (increasing with age). UI is at least twice as prevalent in women as compared with men.[1] Considering the ageing population a further increase is expected.[1] UI is infamous for its impact on general well being and social activities. If not treated and monitored, UI is a chronic dynamic disorder, complicated by co-morbidities, with a strong tendency to increase over time.[1,2] National and international primary care guidelines on UI indicate that for most UI patients pelvic floor muscle and/or bladder training is the best noninvasive initial treatment to solve the problem.[2, 3] So far, despite guidelines, training is only incidentally offered.[4-6] Most GPs choose a non-curative alternative: prescribing incontinence pads. More than $50 \%$ of UI patients use incontinence pads, especially older people.[6, 7]

Although UI threatens health-related quality of life, it is not life threatening.[6, 7] Adequate treatment of UI can be complex and time consuming. So far, UI has not been receiving much attention in general practice, despite the large number of patients who suffer from it.

Probably, there are several reasons, such as lack of knowledge, other clinical priorities, lack of time and lack of targeted implementation strategies to adopt and practice guideline recommendations.[4, 5, 8-12] Therefore, employing nurse specialists may offer a solution to improve the quality of care in general practice provided to UI patients. We envisioned that nurse specialists, after thorough training, would be well equipped to support GPs after the initial consultation and assessment of a UI patient by the GP. Nurse specialists have specific skills and have extra time to inform and motivate patients compared to GPs. Their general 
acceptance by patients and GPs, feasibility, usefulness in management $[13,14]$ and the specific effectiveness in treating UI have been reported.[15]

However, little information is available from randomised controlled trials (RCT) with longterm follow-up on the effectiveness of involving nurse specialists for UI compared to usual care in general practice.[15, 16] Therefore, we set up a trial to study whether involving nurse specialists for UI could improve the quality of care for adult UI patients in general practice.[17] We envisioned that this change in process of care would also improve quality of care in terms of treatment outcome.

We addressed the following main research question: "Does the involvement of a nurse specialist for adult persons with UI reduce the overall UI severity including symptoms of frequency, volume and the impact on the health-related quality of life compared to care-asusual?".

\section{Materials and Methods}

From May 2005 until March 2008 we performed a pragmatic multicentre RCT comparing UI patients (randomly assigned following simple randomisation procedures) receiving nurse specialist care with UI patients receiving care-as-usual in general practice in four Dutch regions (Maastricht, Nijmegen, Helmond, The Hague). A detailed study protocol and description of the intervention is reported elsewhere.[17] In short, adult patients with stress, urgency or mixed UI, already known or newly diagnosed by their GP, were eligible and actively recruited by their GP to participate in the study and followed during one year. To identify patients known to suffer from UI, GPs searched in their electronic medical record system using the International Classification of Primary Care (ICPC) coding system and obtained a list with pad users from the local pharmacies. Patients who met the in- and exclusion criteria were invited to participate in the trial (Table 1). Randomisation was 
computer-generated, with allocation concealment by sealed envelopes. Blinding patients and health care providers was obviously not possible.

Based on a mean UI severity sum score on our primary outcome, the International Consultation on Incontinence Questionnaire Short Form (ICIQ-UI SF),[18] of 7.18 (sd 6.64), an expected clinical important improvement of two points on the outcome scale (delta value of $2 / 6 \cdot 64=0.301$ ), a power of $80 \%$ and a two-sided significance level of 0.05 , we needed 175 patients per arm, 350 in total.

\section{Intervention}

Six nurse specialists provided the intervention (Figure 1). The nurse specialists received special training in tasks related to diagnostics, intervention and monitoring of incontinence based on guidelines and protocols and proved their competencies afterwards in an assessment. After the initial medical UI diagnosis by the GP, the nurse specialists, further specified the diagnosis, registered problems in pelvic floor/bladder function (impairment), activities (disability), participation problems and the influence of personal and external factors following the International Classification of Functioning, Disability and Health (ICF).[19] The nurses used micturition diaries and advised on lifestyle, toilet habits, bladder- and pelvic floor muscle training and, when appropriate, the choice of incontinence pads. Patients were treated during one year, with five to seven visits during the first three months, followed by consultations at six and 12 months to monitor effect and adherence. Details of the training of the nurse specialists and the intervention are described and free full text available elsewhere. 
| IJCP RCT 20112010revised14012011

1

2

3

4

5

6

7

8

9

\section{Care-as-usual}

Patients randomised to care-as-usual could not get a referral to the nurse specialist. We assumed that GPs would not change their care-as-usual, which is mostly restricted to pads prescription, where only a minority of UI patients gets active treatment or a referral to either physical therapist or specialist. $[8,10,11,20]$

\section{Outcome measures}

The primary outcome was the International Consultation on Incontinence Questionnaire Short Form (ICIQ-UI SF) severity sum score of self-reported UI frequency, perceived UI quantity (weighted items) and the UI impact on health-related quality of life (Visual Analogue Scale (VAS).[18] Overall score ranges from zero (no UI) to 21 (most severe UI). UI definitions followed International Continence Society (ICS) standards.[21]

Effects were controlled for accepted baseline effect modifiers (conditions or risk factors that may influence the effects, such as age, UI type, parity, type of delivery, BMI, restricted mobility, anxiety/depression).[1]

The self-completed EuroQol health-related quality of life questionnaire (EQ-5D), provided a five dimensional descriptive profile of mobility, self-care, usual activities, pain/discomfort and anxiety/depression for general health status.[22] Each dimension had three levels: no, some or severe problems.

Data collection and statistical analysis

Data was collected through postal questionnaires at baseline and for the two study end-points, three and 12 months. Non-responders were reminded by telephone two to three weeks later. Kolmogorov-Smirnov tests were used to test normality of distributions in metric variables. Comparability of groups at baseline was checked for demographics, medical history, and 
general health. To test the overall effects in outcome at three months paired t-tests of differences with baseline were used by summing results over both groups. Repeated measures ANOVA was used to test outcome time differences from baseline between both groups, both at three months and for the duration of the total follow-up. Repeated measures ANCOVA was used to adjust for baseline outcome measurements, UI type, age, BMI, parity, complications at delivery and baseline EuroQol scales mobility and anxiety/depression. Dummy regression analysis was used on both the three months difference in outcome and on the linear-weighted trend over all outcome measurements in time. To test overall one-year follow-up results for both groups a one-sample t-test was done on the linear weighted trend. Missing data were imputed by using the mean of observed scores for both groups. A p-value of less than 0.05 was assumed to be statistically significant. Data analysis was done according intention-totreat principles, using SPSS-pc 15.0 and 16.0.

\section{Results}

109 GPs in 65 practices participated. They identified 4055 UI patients. As expected because of the broad recruitment strategy $47 \%(\mathrm{n}=1889)$ had exclusion criteria (mostly comorbidities) for the study. The remaining 2166 patients were invited to participate. 667 Patients were interested and wished to be informed; 206 then refused and 77 were excluded due to co-morbidities.

Finally, 384 patients met the study criteria; 186 were randomly allocated to the intervention and 198 to care-as-usual (Figure 2).

Over the study period 40 (10.4\%) (19 intervention, 21 control) patients dropped out. 
| IJCP RCT 20112010 revised14012011

1

2

3

4

5

6

7

8

9

10

Both groups were comparable for factors such as age, gender, parity etc (Table 2). No separate analysis could be performed for gender since only very few males participated in the study.

Of the 186 patients randomised to the nurse specialist, 137 (73.6\%) had seven to nine consultations (mean time spent 3.1 hours). Fewer consultations were related to poor health $(\mathrm{n}=$ 14) or no motivation/too much burden $(n=15)$. Adverse events were unrelated to the nurse intervention.

\section{Main results}

Overall, both the difference between both groups in ICIQ score at three months and the one-year linear trend was not significant $(\mathrm{p}=0.06$ and $\mathrm{p}=0.15$ respectively) (Table 3 ). In contrast to our expectations, patients in both groups improved on the ICIQ score at three months and on the oneyear linear trend (both endpoints $\mathrm{p}<0.001$ ). However, when controlling for the accepted effect modifiers UI type, BMI and baseline ICIQ score we found that, compared to the care-as-usual group, the ICIQ score differences at three months significantly improved in the intervention group $(\mathrm{B}=-0.56, \mathrm{p}=0.04 ; \mathrm{n}=381)($ Table 3$)$.

Neither BMI, nor UI type was significantly related to the one-year linear trend of the ICIQ score.

\section{Relation with general health}

As suggested in literature, we checked the influence of aspects of general health on improvements of the ICIQ sum scores, but found no influences, except for anxiety/depression. Although no differences after three months were found, after one year anxiety/depression was responsible for less improvement of the ICIQ sum score (interactive effect $\mathrm{B}=1.02, \mathrm{p}=0.03$; $\mathrm{n}$ 
| IJCP RCT 20112010revised14012011

$=381 ; \mathrm{B}$ effect for patients without baseline anxiety/depression $=-.63, \mathrm{p}=0.03 ; \mathrm{n}=272)($ Table

$3)$.

Discussion

Summary of main findings

Significant differences between groups in favour of the intervention group were found after correction for known effect modifiers (UI type and BMI) after three months intervention. Surprisingly, both study groups improved in ICIQ sum score at three months and the one-year linear trend. Also, after one year of intervention we found effects in specific situations (anxiety/depression). Before drawing any conclusion a few remarks must be made.

\section{Strenghts and limitations of the study}

The choice for a pragmatic design ensured that the intervention was as close as possible to treatment options in daily practice. This will facilitate future implementation. We enrolled patients in our study who were typical for the normal GP-caseload. Nevertheless, in terms of external validity, our results may only be valid for patients with a more than mild UI or who are prepared to play an active role towards their UI. As already mentioned our study population had a higher mean baseline ICIQ sum score (11) as compared to the mean sum-score of 7 for a primary care UI population as used in our power calculation, [23] It is generally assumed that

Deleted: this Deleted: This may also be related to the fact

Deleted: that

Deleted: than reported elsewhere mild UI forms do profit most from bladder and pelvic floor muscle training. Our results however, show that also UI patients with severe or complex UI can profit from this intervention.[24-26] In patients with mild UI, the effects of our intervention may be higher.

The assumption prior to the study was that the care-as-usual group -as in many years beforewould stay unchanged during the one-year study period.[27, 28] Given this assumption, the 
| IJCP RCT 20112010revised14012011

1

2

3

4

5

current recruitment numbers should have been sufficient to trace a significant difference. However, reality was different. Unexpectedly, the care-as-usual group also improved on the main outcome parameter. Consequently, the difference between both groups on the outcome became lower than expected. This would signify an unforeseen study effect that might be caused by several factors. GPs may have changed their care-as-usual policy, now being aware their UI approach is monitored (Hawthorne-effect). Theoretically, contamination might have occurred, but from our data we have no indication that this indeed occurred. A learning effect in GPs is in our view unlikely as the average GP included (only) 6 patients in the trial. Next to this, patients in the care-as-usual group may be influenced by being actively recruited for the study. An increased awareness about possible solutions for their UI problem may have occurred by extra contact with the GP for enrolment, the informed consent procedure and by repeatedly completing voiding diaries and questionnaires.[29, 30] Finally, the general mean imputation of missing items for the intention-to-treat-analysis leads to a regression to the mean in effects.

Altogether, when any improvement in the care-as-usual group was to be factored in for the power calculation, more patients would have been needed. As a result, our findings may be quite conservative.

\section{Comparison with existing literature}

This is one of few pragmatic RCTs comparing nurse involvement for UI patients supplementary to care-as-usual by GPs with a long term follow-up of one year.[15, 16] Our findings are in line with RCTs of nurse interventions for incontinent community-dwelling patients.[15, 16] However, comparability of results is limited due to varying populations, settings, outcome measurements, controls, nurse education level and duration of follow-up (often less than one year). Also, our finding that baseline reported anxiety/depression was associated with less UI 
| IJCP RCT 20112010revised14012011

improvement is in line in literature.[31-33] Lack of motivation, especially in those suffering from depression, might explain the lack of effect of our intervention on the one-year linear trend. Implications for clinical practice and future research

UI is a chronic dynamic disorder and often complicated by comorbidities.[1] The positive effect of the nurse specialist intervention on the short term would argue in favour of a repeated intervention by trained health care professionals to monitor the condition and achieve long term effects.[34]

Further research should focus on tailoring the intervention to patients characteristics which are prognostic and predictive for UI and changeable (depression[1, 31, 33], overweight[1, 35]). Also, research into the cost-effectiveness of involving nurse specialists for UI patients in general practice is needed.[36] 
| IJCP RCT 20112010 revised14012011

1

2

3

4

5

6

7

8

9

10

\section{Acknowledgments}

We thank all participating GPs and Zorg Groep Zuid-Gelderland, Groene Kruis Domicura, Maastricht, AZIVO/ PCC of HAGA Hospital, The Hague, De Zorgboog, Elkerliek Hospital, Helmond, The Netherlands, their nurse specialists and the patients for their cooperation in the study. We thank Wendy Engering, Margriet Straver, Liesbeth van Hoef, Joyce Janssen and Nicole Castro for research assistance.

\section{Funding}

The study was approved and funded by the Netherlands Organisation for Health Research and Development (ZonMw), grant number 945-04-224. ZonMw was not involved in manuscript preparation and/or publication decisions.

\section{Author contributions}

All authors have approved the final draft for submission and had access to the study data.

Specific contributions were made in the following area's: Pytha Albers-Heitner was involved in the conception and design of the study, data collection, statistical analysis and interpretation. In addition, she was responsible for the preparation, drafting and critical revision and approval of the manuscript. Toine Lagro-Jansen was helpful in the conception and design of the study, facilitated data collection, supervised the project, participated in the data interpretation, preparation and critical revision of the manuscript for important intellectual content and approval. Manuela Joore assisted in the conception and design of the study, supervised the project and critically revised the drafts of the manuscript for important intellectual content and approval. Bary Berghmans was responsible for the conception and design of the study, facilitated 
| IJCP RCT 20112010

data collection, supervised the project, participated in the data interpretation, preparation and critical revision and approval of the manuscript for important intellectual content. Fred Nieman was helpful in the conception and design of the study, was responsible for methodology and the statistical analysis and interpretation, and was involved in revising and approval of the manuscript for important intellectual content. Pieter Venema was helpful in the conception and design of the study, facilitated data collection and critically revised and approved the final drafts of the manuscript for important intellectual content.

Johan Severens gave advice regarding the conception and design of the study, supervised the project, advised in data analysis and interpretation and was involved in revising and approval of the manuscript for important intellectual content. Ron Winkens (project leader) was responsible for the conception and design of the study, supervised the project, facilitated data collection, participated in the data interpretation, preparation and critical revision and approval of the manuscript for important intellectual content. 
References

1. Milsom I, Altman D, Lapitan M et al. Committee 1. Epidemiology of Urinary (UI) and Faecal (FI) Incontinence and Pelvic Organ Prolapse (POP). Fourth International Consultation on Incontinence (ICI) - July 5 - 8, 2008 Palais des Congres, Paris, France. Paris, France Health Publication Ltd 2009:63, 72, 89-92.

2. Abrams P, Cardozo L, Khoury S, Wein A. Fourth International Consultation on Incontinence (ICI) - July 5 - 8, 2008. Palais des Congres, Paris, France. Paris, France Health Publication Ltd 2009.

3. Hay Smith J, Berghmans B, Burgio K et al. Committee 12. Adult Conservative Management. Fourth International Consultation on Incontinence (ICI) - July 5 - 8, 2008 Palais des Congres, Paris, France. Paris, France: Health Publication Ltd 2009:1079, 80; 94.

4. Wagg A, Cardozo L, Chapple C et al. Overactive Bladder and Continence Guidelines: implementation, inaction or frustration? International Journal of Clinical Practice. 2008;62(10):1588-93.

5. Kirby M, Artibani W, Cardozo L et al. Overactive bladder: the importance of new guidance. Int J Clin Pract. 2006;60(10):1263-71.

6. Monz B, Pons M, Hampel C et al. Patient-reported impact of urinary incontinence. Results from treatment seeking women in 14 European countries. Maturitas. 2005;30(52):suppl 2; 24-34.

7. Coyne K, Sexton C, Irwin D et al. The impact of overactive bladder, incontinence and other lower urinary tract symptoms on quality of life, work productivity, sexuality and emotional well-being in men and women: results from the EPIC study. BJU Int. 2008;101(11):1388-95.

8. Kirby M. Managing stress urinary incontinence - a primary care issue. Int J Clin Pract. 2006;60(2):184-9.

9. Shaw C, Atwell C, Wood F et al. A qualitative study of the assessment and treatment of incontinence in primary care. Fam Pract. 2007;24(5):461-7.

10. Albers-Heitner P, Berghmans B, Nieman F et al. Adherence to professional guidelines for patients with urinary incontinence by general practitioners: a cross-sectional study. Journal of Evaluation in Clinical Practice. 2008; 14(5):807-11.

11. Albers-Heitner P, Berghmans B, Nieman F et al. How do patients with urinary incontinence perceive care given by their general practitioner? A cross-sectional study. Int J Clin Pract. 2008;62(3):508-15.

12. Staskin DR. The five 'Ps' of an incontinence clinical practice guideline. International Journal of Clinical Practice. 2008;62(10):1466-7.

13. Laurant M, Harmsen M, Faber M et al. Revision of professional roles and quality improvement: a review of the evidence. London: The Health Foundation.2010. 
14. Voogdt-Pruis H, Beusmans G, Gorgels A et al. Effectiveness of nurse delivered cardiovascular risk management in primary care: a randomised trial British Journal of General Practice 2010;60:40-6.

15. Du Moulin MFMT, Hamers JPH, Paulus A et al. The role of the nurse in community continence care: a systematic review. Int J Nurs Stud. 2005 5;42(4):479-92.

16. Du Moulin MFMT, Hamers JPH, Paulus A et al. Effects of Introducing a Specialized Nurse in the Care of Community-Dwelling Women Suffering From Urinary Incontinence: A Randomized Controlled Trial. J Wound Ostomy Continence Nurs. 2007;34(6):631-40.

17. Albers-Heitner P, Berghmans B, Joore M et al. Study protocol. The effects of involving a nurse practitioner in primary care for adult patients with urinary incontinence: the PromoCon study (Promoting Continence). BMC Health Serv Res 2008(8):84

18. Avery K, Donovan J, Peters T et al. ICI-Q: a brief and robust measure for evaluating the symptoms and impact of urinary incontinence. Neurourol Urodyn. 2004;23(4):322-30. http://www.iciq.net/ICIQ-UIshortform.html; accessed 18-08-2010.

19. World Health Assembly Resolution 54.21. International Classification of Functioning, Disability and Health (ICF). http://www.who.int/classifications/icf/en/. 200122 may 2010 [cited 2010 20-08]; Available from:

20. Gerwen van M, Schellevis F, Lagro-Janssen T. Management of urinary incontinence in general practice: data from the Second Dutch National Survey. J Eval Clin Pract. 2009; 15: 341-5.

21. Haylen BT, De Ridder D, Freeman RM et al. An international urogynecological association (IUGA)/international continence society (ICS) joint report on the terminology for female pelvic floor dysfunction. Neurourol Urodyn. 2010;29(1):4-20.

22. Brooks R. EuroQol: the current state of play. Health Policy. 1996;37(1):53-72.

23. Abrams P, Cardozo L, Khoury S, Wein A. Incontinence Proceedings 2nd International Consultation on Incontinence - July 1, 2001- July 3, Paris. 2002:976.

24. Klovning A, Avery K, Sandvik H, Hunskaar S. Comparison of two questionnaires for assessing the severity of urinary incontinence: The ICIQ-UI SF versus the incontinence severity index. Neurourol Urodyn. 2009 February 12;28(5):411-5.

25. Shaw C, Brittain K, Tansey R, K. W. How people decide to seek health care: A qualitative study. Int J Nurs Stud. 2008;45(10):1516-24.

26. Dumoulin C, Hay-Smith J. Pelvic floor muscle training versus no treatment, or inactive control treatments, for urinary incontinence in women. Cochrane Database of Systematic Reviews 2010, Issue 1. Art. No.: CD005654. DOI: 10.1002/14651858.CD005654.pub2.

27. McGrother C, Donaldson M, Shaw C et al. Storage symptoms of the bladder: prevalence, incidence and need for services in the UK. BJU Int. 2004;93(6):763-9.

28. Wennberg A-L, Molander U, Fall M et al. A Longitudinal Population-based Survey of Urinary Incontinence, Overactive Bladder, and Other Lower Urinary Tract Symptoms in Women. Eur Urol. 2009 april;55(4):783-91.

29. Burgio KL, Goode PS, Locher JL et al. Behavioral Training With and Without Biofeedback in the Treatment of Urge Incontinence in Older Women: A Randomized Controlled Trial. JAMA 2002 November 13, 2002;288(18):2293-9.

30. Melville JL, Katon W, Delaney K, Newton K. Urinary Incontinence in US Women: A Population-Based Study. Arch Intern Med. 2005;165(5):537-42. 
31. Nygaard I, Turvey C, Burns TL et al. Urinary incontinence and depression in middleaged United States women. Obstet Gynecol. 2003;101(1):149-56.

32. Gerwen van M, Schellevis F, Lagro-Janssen T. Comorbidities Associated with Urinary Incontinence: A Case-Control Study from the Second Dutch National Survey of General Practice. J Am Board Fam Med 2007;20:608-10.

33. Melville JL, Fan M-Y, Rau H et al. Major depression and urinary incontinence in women: temporal associations in an epidemiologic sample. Am J Obstet \& Gynecol. 2009;201:490.e1-7.

34. Holroyd-Leduc JM, Straus SE. Comment on: Is there a role for estrogen in the prevention and treatment of urinary incontinence? CMAJ. 2005 April 12, 2005;172(8):1003-4.

35. Subak LL, Wing R, West DS et al. Weight loss to treat urinary incontinence in overweight and obese women. N Engl J Med. 2009;360(5):481-90.

36. Moore K, Wei Hu T, Subak L et al. Committee 22. Economics of Urinary and Faecal Incontinence, and Prolapse. Fourth International Consultation on Incontinence (ICI) July 5 - 8, 2008 Palais des Congres, Paris, France. Paris, France Health Publication Ltd 2009:1708, 9. 
Figure 1. Flow chart intervention nurse specialist for patients with UI PFM (T)= Pelvic Floor Muscle (Training); GP = general practitioner; PPT = pelvic physiotherapist; NS = nurse specialist Definitions following International Continence Society (ICS) standards.
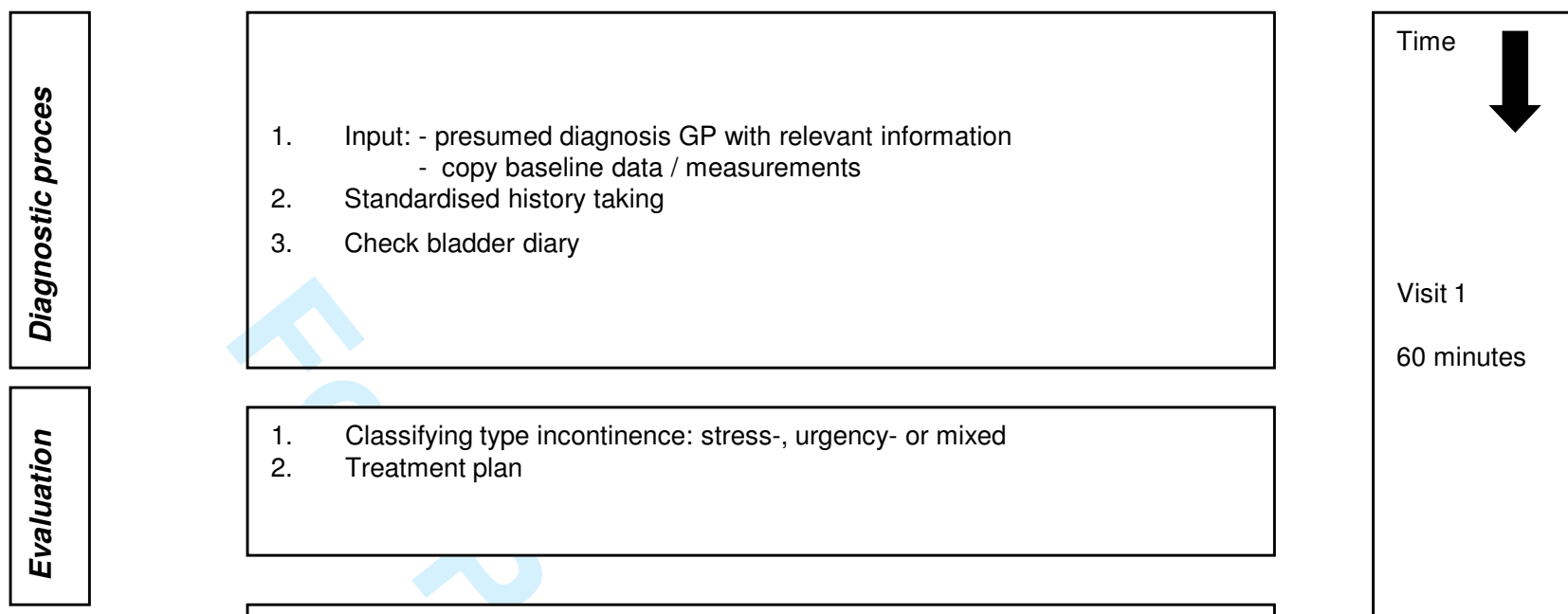

1. Classifying type incontinence: stress-, urgency- or mixed

2. Treatment plan
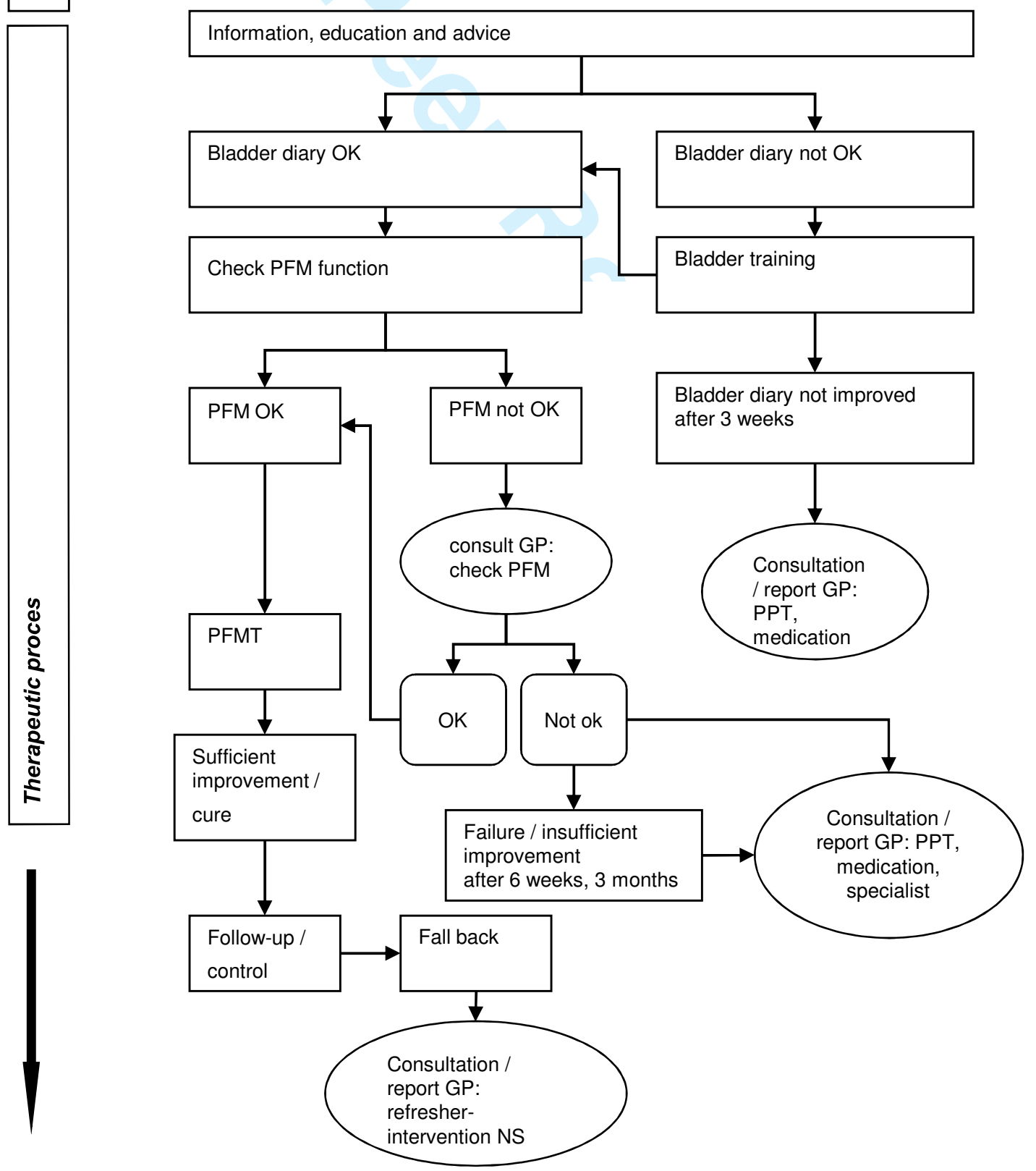

3-5x weekly visites 20 minutes

Follow-up contact 15 minutes at 6 weeks

3 months 
Figure 2. Flow of participants through each stage of the randomised trial and analysed for primary outcome

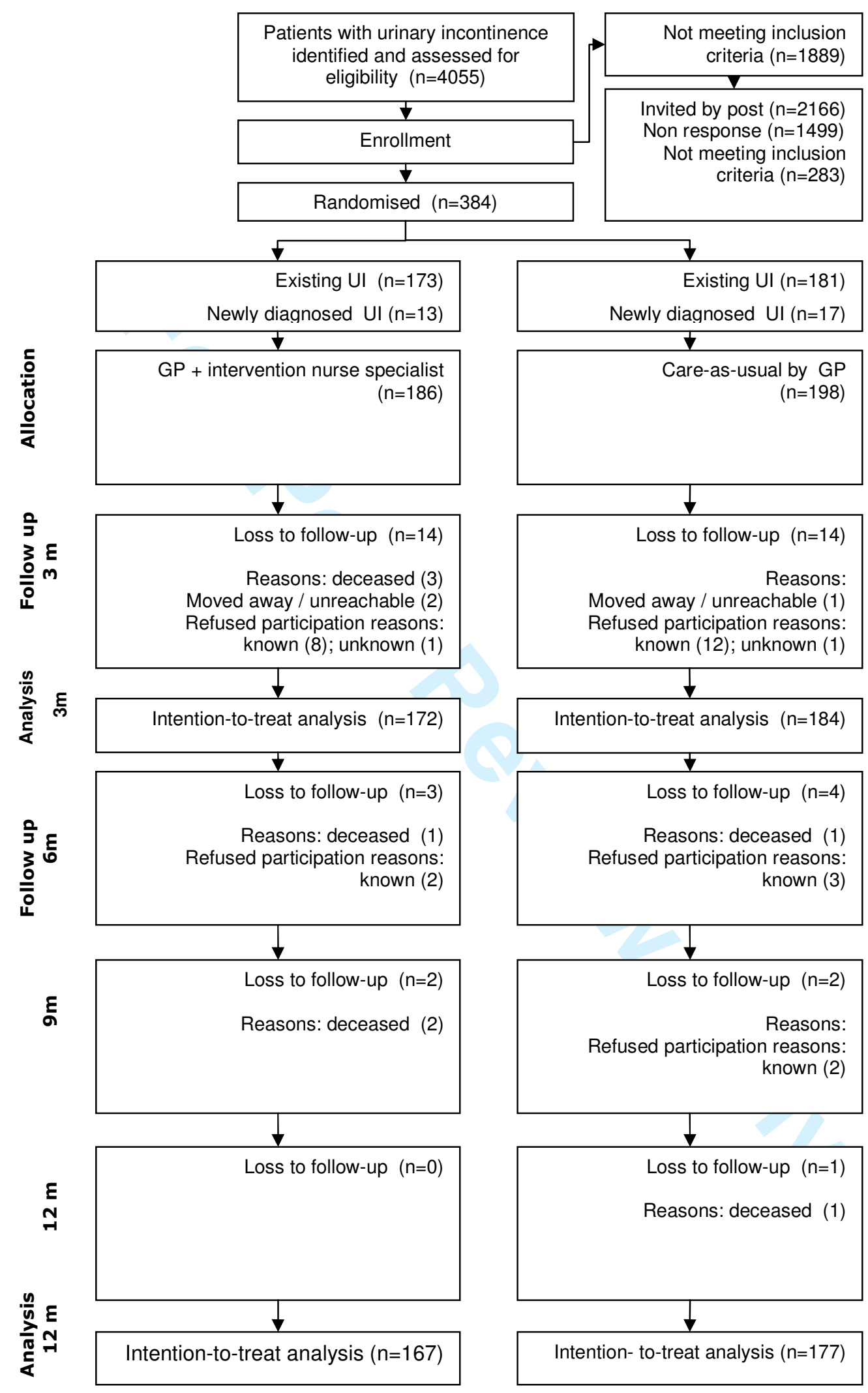


Table 1. In- and exclusion criteria

\section{Inclusion criteria}

- age $\geq 18$ years

- SUI, UUI or MUI already or newly diagnosed by GP (according to the guidelines of the Dutch College of General Practitioners on UI)

\section{Exclusion criteria}

- women with prolapse degree III or more

- pregnancy or delivery $<6$ months ago

patients with

- other types of UI than SUI, UUI or MUI / signs of reflex- or overflow UI

- abdominal tumors

- neurological diseases associated with UI (multiple sclerosis, stroke, diabetes, cauda equina syndrome)

- urinary tract infection, hematuria without urinary tract infection

- male $<65$ years with unclear reason for UI

- ongoing other treatment for UI

- failure after surgery for UI or failure of conservative therapy

- severe cognitive problems

- living in nursing home

- otherwise severe medical or psychiatric diseases

- comprehension of Dutch language not good enough to fill in questionnaires

Abbreviation: $\mathrm{SUI}=$ stress urinary incontinence; $\mathrm{UUI}=$ urgency urinary incontinence; $\mathrm{MUI}=$ mixed urinary incontinence; Ul=urinary incontinence; GP=general practitioner 


\begin{tabular}{|c|c|c|c|}
\hline \multirow{2}{*}{\multicolumn{2}{|c|}{ CHARACTERISTIC }} & \multirow{2}{*}{$\begin{array}{r}\text { INTERVENTION group } \\
\qquad=186(48.4 \%)\end{array}$} & \multirow{2}{*}{$\begin{array}{r}\text { USUAL CARE group } \\
\qquad N=198(51.6 \%)\end{array}$} \\
\hline & & & \\
\hline Female $\mathrm{n}(\%)$ & & $171(91.9)$ & $184(92.9)$ \\
\hline Age mean $\pm s d$ & & $64.5(14.1)$ & $64.9(11.6)$ \\
\hline \multirow[t]{2}{*}{$\mathrm{BMI}$ mean $\pm \mathrm{sd} \mathrm{kg} / \mathrm{m} 2$} & & $28.3(6.5)$ & $28.1(5.8)$ \\
\hline & & $6 \mathrm{mv}$ & $7 \mathrm{mv}$ \\
\hline \multirow[t]{5}{*}{ Type UI n (\%) } & SUI & $68(36.6)$ & $67(34.4)$ \\
\hline & UUI & $30(16.1)$ & $34(17.4)$ \\
\hline & Mixed & $71(38.2)$ & $78(40.0)$ \\
\hline & NOS & $17 \quad(9.1)$ & $16(8.2)$ \\
\hline & & & $3 \mathrm{mv}$ \\
\hline Prolapse problems $\mathrm{n}(\%)$ & & $24(12.9)$ & $26(13.1)$ \\
\hline Constipation n (\%) & & $52(28.0)$ & $42(21.2)$ \\
\hline $\mathrm{FI} \mathrm{n} \mathrm{( \% )}$ & & $33(17.7)$ & $38(19.2)$ \\
\hline \multirow[t]{4}{*}{ MOBILITY (\%) } & No problems & 59.1 & 57.6 \\
\hline & Problems* & 40.9 & 42.4 \\
\hline & No problems & 89.2 & 93.4 \\
\hline & Problems & 10.8 & 6.6 \\
\hline \multirow[t]{2}{*}{ USUAL ACTIVITIES (\%) } & No problems & 69.4 & 61.1 \\
\hline & Problems & 30.7 & 38.9 \\
\hline \multirow[t]{2}{*}{ PAIN/DISCOMFORT (\%) } & No problems & 48.8 & 46.5 \\
\hline & Problems & 55.8 & 53.5 \\
\hline \multirow[t]{2}{*}{ ANXIETY/DEPRESSION (\%) } & No problems & 71.5 & 74.2 \\
\hline & Problems & 28.5 & 25.7 \\
\hline
\end{tabular}

\footnotetext{
Abbreviation: $\mathrm{mv}=$ missing value; $\mathrm{BMl}=$ body mass index, calculated as weight in kilograms divided by height in meters squared; $\mathrm{UI}=$ =urinary incontinence; $\mathrm{SUI}=$ stress urinary incontinence; $\mathrm{UUI}=$ urgency urinary incontinence; $\mathrm{MUI}=$ mixed urinary incontinence; $\mathrm{NOS}=$ not otherwise specified; $\mathrm{FI}=$ fecal incontinence *problems=sum of moderate and severe problems
} 
Table 3. Results intention-to-treat repeated measures Ancova /regression analysis on ICIQ-UI SF sum score;

a higher score means more severity and impact of urinary incontinence

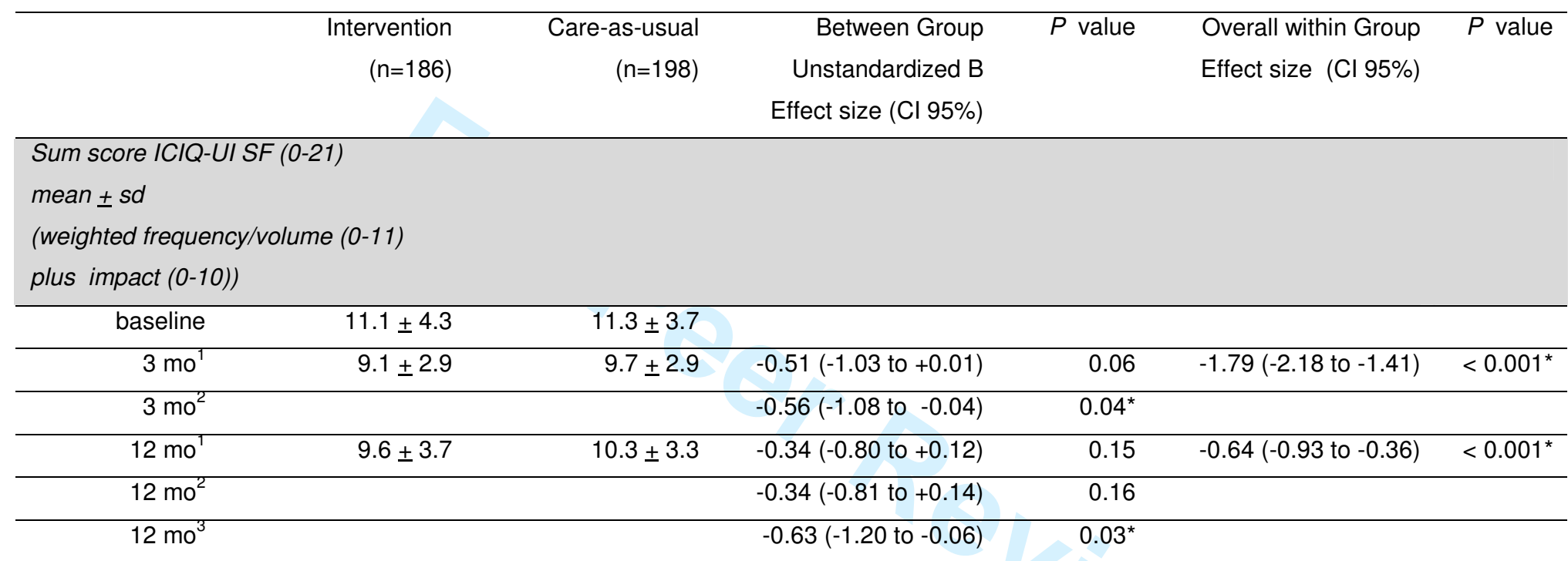

${ }^{1}$ Model $=$ stimulus effect adjusted for baseline differences

${ }^{2}$ Model $=$ stimulus effect controlled for BMI, type UI, baseline sum score, and type UI*baseline sumscore $(n=381)$

${ }^{3}$ Model $=$ same model as under 2 , but for patients without baseline mental health problems anxiety/depression $(n=272)$

Abbreviations: ICIQ-UI SF=International Consultation Incontinence Questionnaire Short Form; mo=month(s); yr=year;

$\mathrm{BMI}=$ body mass index, calculated as weight in kilograms divided by height in meters squared; typeUl=type of urinary incontinence

*statistically significant improvement 